\title{
Influence of High and Low Saturated Fatty Acid-Based Diets on Weight and Body Composition of Albino Rats (Rattusnorvegicus)
}

\author{
Folorunso $\mathrm{OP}^{1}$, Uzuh $\mathrm{FD}^{2}$, Ayeni $\mathrm{TS}^{2}$ and Abere $\mathrm{DV}^{2 *}$ \\ ${ }^{1}$ Department of Zoology, Obafemi Awolowo University, Nigeria \\ ${ }^{2}$ National Metallurgical Development Centre, Nigeria
}

*Corresponding author: Dare Victor Abere, National Metallurgical Development Centre, Jos, Nigeria, Email: aberevictor@gmail.com

\section{Research Article \\ Volume 5 Issue 4}

Received Date: September 09, 2020

Published Date: October 05, 2020

DOI: $10.23880 /$ oajmb-16000172

\section{Abstract}

The study investigated the effect of feeding high and low saturated fatty acid based diets to feed female albino rats (Rattus norvegicus) with a view to evaluating the effects of the fatty diets on the feeding patterns, weight and body composition of the rats. Seven months old female Rattus norvegicus were used for the experiment. The weights of the rats were taken for twelve weeks using Salter balance (Model 250). Four experimental diets were formulated which were made up of 2.5 and $5.0 \mathrm{~g}$ of margarine (blue band), 2.5 and $5.0 \mathrm{~g}$ canola oil each mixed with the basal diet. The control diet was grower feed and the resultant experimental diets were fed to the experimental rats kept in cages at the rate of 12 rats per cage. The rats were fed with the diets at the rate of $3 \%$ of body weight for a period of twelve weeks. The highest weight gain was recorded in the group fed with $5.0 \mathrm{~g}$ margarine, followed by $5.0 \mathrm{~g}$ canola, $2.5 \mathrm{~g}$ margarine, $2.5 \mathrm{~g}$ canola and least in the rats fed the control. The mean weight gain of the rats fed with $5.0 \mathrm{~g}$ margarine and $5.0 \mathrm{~g}$ canola were significantly different $(\mathrm{p}<0.05)$ from the mean weight of $2.5 \mathrm{~g}$ margarine, $2.5 \mathrm{~g}$ canola and the control. The food intake of the rats fed $5.0 \mathrm{~g}$ margarine and $5.0 \mathrm{~g}$ canola was also significantly different $(\mathrm{p}<0.05)$ from the food intake of rats fed $2.5 \mathrm{~g}$ margarine, $2.5 \mathrm{~g}$ canola and the control. The proximate composition of the carcass of the rats fed the different experimental diets showed that fat content of the rats fed $5.0 \mathrm{~g}$ margarine was higher than in the rats fed the other diets. The histology of the liver of rats fed $5.0 \mathrm{~g}$ margarine and 5.0 $\mathrm{g}$ canola showed greater fat accumulation in the rat's liver compared to rats fed $2.5 \mathrm{~g}$ margarine, $2.5 \mathrm{~g}$ canola as well as the control. Rats with the highest body weight gain were considered obesity-prone; those with the lowest body weight were regarded as obesity-resistant while others were considered intermediate. The study concluded that the kind of fat consumed contributes to the weight gained by the rats.

Keywords: Rattus Norvegicus; Diets; Weight; Control; Canola; Fat; Histology; Obesity

Abbreviations: SPSS: Statistical Package for Social Science; ANOVA: Analysis of Variance

\section{Introduction}

The body needs to consume fat in order to work properly
$[1,2]$. Fat comes from a variety of food groups, particularly the milk, meat, and oils food groups [3] but can also be found in many fried foods, baked foods, and pre-packaged foods. Fat is a major source of energy and helps the body absorb fat soluble vitamins [4]. It is also important for proper growth, and healthy living. A completely fat-free diet would not be 


\section{Open Access Journal of Microbiology \& Biotechnology}

healthy, yet it is important that fat be consumed in moderation. Fat has the most calories compared to any other nutrient, so controlling fat intake is one of the most important steps in losing or maintaining weight and preventing or delaying type 2 diabetes. High-fat diets are known to lead to a positive fat balance and consequently to adipose mass accumulation [5]. This has often been used successfully for modelling the metabolic disorders of human obesity in rodents, which enhances the belief that the development of obesity is due to excess energy intake. Several studies have been conducted to understand the complex central and peripheral networks that regulate food intake in order to identify potential targets for effective anti-obesity therapy [6]. An increase in carbohydrate and/or protein consumption is accompanied by increased oxidation rates of both nutrients. On the other hand, the balance between fat consumption and oxidation rates is not so tightly regulated and depends on the type of fatty acids [3]. High-fat diets are associated with increased risk of several serious medical conditions including obesity, cancer, and heart disease [7], hence this study.

\section{Materials and Methods}

\section{Diet Preparation and Experimental Design}

Sixty albino rats (Rattusnorvegicus) were obtained from Pharmacology Department, Obafemi Awolowo University, Nigeria and were weighed using Salter balance (Model 250). The proximate compositions of the rat fillet were determined according to standard procedures of Association of Official Analytical Chemists [8]. The proximate composition of blue band (margarine), Canola oil and the fibre feed was done in the Department of Food Science and Technology, Obafemi Awolowo University. Four experimental diets were formulated to contain 2.5 and 5.0 g margarine, 2.5 and $5 \mathrm{~g}$ canola each mixed with the basal diet. The control diet was grower feed and the resultant experimental diets were fed to the experimental rats over a period of twelve weeks in a cage at 12 rats per cage. The initial and final weights of the rats were taken to monitor the effect of the different diets on the weights of the rats. At the end of the experimental feeding, the proximate composition of the rat carcasses (Table 1) was done in the Department of Food Science and Technology, Obafemi Awolowo University, Ile-Ife to analyze the components of the rats in order to justify the weight gained by the rats.

\section{Experimental Feeding and Measurements}

Sixty, 7 months old female albino rats (Rattusnorvegicus) obtained from the Pharmacology Laboratory, Obafemi Awolowo University, Ile-Ife were used for the experiment. The rats were distributed in cages according to the four experimental treatment and control and fed with grower feed and water for one week to ensure the rats have the same nutritional history at the rate of $3 \%$ of their body weight per week. The rats were fed the diet at the rate of $3 \%$ of body weight and both the experimental diets and the control diet were. The entire rats were starved for 24 hours prior to the beginning of the experimental feeding to allow for the digestion of already eaten food and also prepare the rats for the test diets. The rats in each treatment were weighed at the beginning of the feeding and weekly subsequently using Salter balance (Model 250). Food allotments were adjusted weekly according to the new body weight changes. Uneaten food and faecal samples were removed weekly while rat mortality was monitored daily. Body weight changes and feed intake were recorded weekly and at the end of the three months feeding two rats from each cage were sacrificed, fillet dissected out. The fillet samples were subjected to proximate analysis [8].

\section{Statistical Analysis}

Statistical package for Social science (SPSS) Version 17.0 was used for statistical analysis. The significant differences between groups were compared using two- tailed analysis of variance (ANOVA).

\section{Results and Discussion}

\section{Proximate Analysis of Experimental Diets}

Table 1 showed the proximate composition of Margarine, Canola and Fibre feed, it revealed the percentage of protein, moisture, fat, ash, crude fibre, carbohydrate and dry matter in the experimental diet. The result was presented in duplicate and the mean values were taken. From the mean values, both margarine and canola had the lowest amounts of protein.

\begin{tabular}{|c|c|c|c|c|c|c|c|}
\hline \multirow{2}{*}{ Sample Code } & \multirow{2}{*}{ Protein\% } & \multirow{2}{*}{ Moisture\% } & Fat & Ash & \multirow{2}{*}{ Crude Fibre\% } & Carbohydrate & \multirow{2}{*}{ Dry Matter\% } \\
\cline { 4 - 5 } & & & $\mathbf{\%}$ & $\mathbf{\%}$ & & $\mathbf{\%}$ & \\
\hline Canola & 0.954 & 0.81 & 88.34 & 1.63 & 0 & 8.275 & 99.19 \\
\hline Margarine & 0.235 & 5.65 & 90.65 & 0.59 & 0 & 2.7 & 94.395 \\
\hline Control & 18.91 & 4.83 & 7.34 & 0.63 & 4.49 & 63.77 & 95.8 \\
\hline
\end{tabular}

Table 1: Proximate analysis of experimental diet. 
Margarine had $0.235 \%$, canola had $0.954 \%$ while the control which was the fibre feed had $18.91 \%$. This showed that the percentage of protein in the experimental diet was highest in the fibre feed but least in margarine as both margarine and canola was less than 1 percent.

The moisture content was lowest in canola, followed by the fibre feed and highest in margarine. The percentage of moisture in the feed which is $4.83 \%$ is close to the percentage of moisture in margarine which is $5.65 \%$ but the percentage of canola which is 0.81 is extremely low compared to the other groups. The result showed no significant difference between the percentage of moisture in margarine and the fibre feed but a significant difference do exist between canola feed and margarine with respect to the control. The outcome of the proximate analysis of the diets showed the percentage of fat in canola to be $88.34 \%$, margarine with $90.65 \%$ and the control having $7.34 \%$. The result showed that the fibre feed which is the control has the least content of fat. However, it is probably one of the reasons responsible for the high weight gained by the group fed margarine and canola. There is close relationship between the percentage of fat in canola and margarine but no relationship existed between the percentage of fat in canola and the control and the percentage of fat in margarine and control [9].
There is no significant difference between the control diet which is the fibre feed and margarine in respect to ash content as both margarine and the control feed are less than $1 \%(0.635 \%, 0.59 \%)$ respectively while canola is $1.63 \%$. The same thing could be observed in crude fibre as both canola and margarine have $0 \%$ and this might be attributed to the fact that there was no residue in them while the fibre feed has little residue with $4.4 \%$ [10].

Carbohydrate has the lowest percentage in margarine with $2.7 \mathrm{~g}$, follow by $8.275 \mathrm{~g}$ in canola and highest in the fibre feed. The reason is probably because the major constituent in canola and margarine is fat and not carbohydrate as it is in the fibre feed.

\section{Weight Gain in Rats}

Tables 2 and 3 showed the result of the initial and final weights of the rats. The rat's weights in the final week in all the groups were higher than the control but a significant difference was observed in the rats fed with $5.0 \mathrm{~g}$ margarine $(\mathrm{P}<0.05)$. The result of the final weight was imputed in SPSS version 17 to determine the differences in the means between and across the group. Table 4 shows the result of the Anova table.

\begin{tabular}{|c|c|c|c|c|c|}
\hline S/N & 5g Margarine & 2.5g Margarine & 5gcanola & 2.5g canola & Control \\
\hline 1 & 70 & 70 & 73 & 62 & 79 \\
\hline 2 & 75 & 80 & 70 & 78 & 65 \\
\hline 3 & 80 & 75 & 67 & 75 & 72 \\
\hline 4 & 74 & 71 & 73 & 80 & 70 \\
\hline 5 & 70 & 70 & 85 & 73 & 73 \\
\hline 6 & 70 & 78 & 65 & 65 & 74 \\
\hline 7 & 75 & 65 & 75 & 70 & 76 \\
\hline 8 & 75 & 74 & 73 & 64 & 76 \\
\hline 9 & 65 & 78 & 68 & 70 & 79 \\
\hline 10 & 70 & 70 & 75 & 70 & 73 \\
\hline 11 & 70 & 71 & 869 & 861 & 68 \\
\hline 12 & 80 & 867 & 72.42 & 71.75 & 876 \\
\hline TOTAL & 72.25 & 75 & 73 \\
\hline MEAN & 72.83 & & 75 & 73 & 73 \\
\hline
\end{tabular}

Table 2: Weight of week one of Rattusnorvegicus. 


\section{Open Access Journal of Microbiology \& Biotechnology}

\begin{tabular}{|c|c|c|c|c|c|}
\hline \multirow{2}{*}{$\mathbf{S} / \mathbf{N}$} & $\mathbf{5 g}$ Margarine & $\mathbf{2 . 5 g}$ & $\mathbf{5 g}$ & $\mathbf{2 . 5 g}$ & \multirow{2}{*}{ Control } \\
\cline { 2 - 5 } & & Margarine & Canola & Canola & 100 \\
\hline 1 & 240 & 180 & 210 & 175 & 190 \\
\hline 2 & 250 & 200 & 195 & 170 & 95 \\
\hline 3 & 260 & 205 & 190 & 165 & 105 \\
\hline 4 & 200 & 195 & 220 & 205 & 190 \\
\hline 5 & 190 & 185 & 245 & 170 & 105 \\
\hline 6 & 255 & 210 & 205 & 160 & 110 \\
\hline 7 & 250 & 185 & 190 & 170 & 120 \\
\hline 8 & 285 & 205 & 220 & 180 & 95 \\
\hline 9 & 180 & 220 & 230 & 160 & 90 \\
\hline 10 & 240 & 195 & 220 & 190 & 110 \\
\hline 11 & 255 & 180 & 195 & 165 & 190 \\
\hline 12 & 275 & 200 & 215 & 200 & 1500 \\
\hline TOTAL & 2880 & 2360 & 2535 & 2110 & 125 \\
\hline MEAN & 240 & 196.66 & 211.25 & 175.83 & 19 \\
\hline
\end{tabular}

Table 3: Weight of week 12 of Rattusnorvegicus.

\begin{tabular}{|c|c|c|c|c|c|c|c|c|}
\hline Variables & \multicolumn{2}{|c|}{ Sum of squares } & \multicolumn{2}{c|}{ Degree of Freedom } & \multicolumn{2}{c|}{ Mean square } & & \\
\hline & $\begin{array}{c}\text { Between } \\
\text { groups }\end{array}$ & $\begin{array}{c}\text { Within } \\
\text { groups }\end{array}$ & $\begin{array}{c}\text { Between } \\
\text { groups }\end{array}$ & $\begin{array}{c}\text { Within } \\
\text { groups }\end{array}$ & $\begin{array}{c}\text { Between } \\
\text { groups }\end{array}$ & $\begin{array}{c}\text { Within } \\
\text { groups }\end{array}$ & F & P-Value \\
\hline Week 1 & 11.767 & 1487.083 & 4 & 55 & 2.942 & 27.038 & 0.109 & 0.976 \\
\hline Week 2 & 94.767 & 1681.167 & 4 & 55 & 23.692 & 30.567 & 0.775 & 0.546 \\
\hline Week 3 & 257.267 & 1724.917 & 4 & 55 & 64.317 & 31.362 & 2.051 & 0.1 \\
\hline Week 4 & 4875.1 & 1553.5 & 4 & 55 & 1218.776 & 28.245 & 43.15 & 0 \\
\hline Week 5 & 10614.433 & 1318.417 & 4 & 55 & 2653.608 & 23.971 & 110.7 & 0 \\
\hline Week 6 & 15185.4 & 2170 & 4 & 55 & 3796.35 & 39.455 & 96.22 & 0 \\
\hline Week 7 & 41318.233 & 6212.75 & 4 & 55 & 10329.558 & 112.956 & 91.45 & 0 \\
\hline Week 8 & 56683.917 & 11373.92 & 4 & 55 & 11470.933 & 206.793 & 68.53 & 0 \\
\hline Week 9 & 68291.167 & 20428.17 & 4 & 55 & 17072.792 & 371.421 & 45.97 & 0 \\
\hline Week 10 & 87126.4 & 31801.33 & 4 & 55 & 21781.6 & 578.206 & 37.67 & 0 \\
\hline Week 11 & 86863.767 & 35299.83 & 4 & 55 & 21715.942 & 641.815 & 33.84 & 0 \\
\hline Week 12 & 89056.667 & 37014.58 & 4 & 55 & 22264.167 & 672.992 & 33.08 & 0 \\
\hline
\end{tabular}

Table 4: Anova showing the significant level of high and low saturated fatty acid on weight gain of Rattusnorvegicus.

\section{Carcass Composition}

The proximate composition of the carcass of the rats fed the different experimental diets varied with treatment (Table 5) and the mean of the proximate composition was shown in (Table 6). The fat content of rats fed $5.0 \mathrm{~g}$ margarine $(10.455 \%)$ was higher than the fat in $5.0 \mathrm{~g}$ canola $(9.975 \%)$ as well as in the other experimental groups. The control group had the least content of fat with $7.585 \%$ compare to the rest of the experimental treatments. 


\section{Open Access Journal of Microbiology \& Biotechnology}

\begin{tabular}{|c|c|c|c|c|c|c|c|}
\hline \multirow{2}{*}{ Sample Code } & Protein & Moisture & Fat & \multirow{2}{*}{ Ash } & \multirow{2}{*}{ Crude Fibre\% } & CHO & \multirow{2}{*}{ Dry Matter\% } \\
\cline { 2 - 5 } & $\mathbf{0}$ & $\mathbf{\%}$ & $\mathbf{\%}$ & $\mathbf{\%}$ & & $\mathbf{\%}$ & \\
\hline GP1 & 18.6 & 65.795 & 10.455 & 2.525 & 0.26 & 2.36 & 34.215 \\
\hline GP2 & 15.71 & 68.52 & 9.97 & 2.385 & 0.2 & 3.215 & 31.48 \\
\hline GP3 & 10.565 & 72.7225 & 7.585 & 2.385 & 0.21 & 6.545 & 27.29 \\
\hline GP4 & 12.755 & 71.14 & 8.2375 & 2.49 & 0.2025 & 5.175 & 28.86 \\
\hline GP5 & 15.36 & 68.86 & 8.795 & 2.4 & 0.22 & 4.375 & 31.14 \\
\hline
\end{tabular}

Table 5: Proximate analysis of Rattusnorvegicus.

\section{Feed Intake}

The rats were well fed for the period of the 12 weeks, the food intake was measured weekly (Table 6) and the Anova table was shown in Table 7. There was a significant difference $(\mathrm{P}<0.05)$ in the food intake of the rats fed high and low saturated fatty acid diet. Rats fed control diet consumed the least amount of the experimental feed while those fed 5.0 g margarine consumed the highest feed. Comparatively, the rats fed the $5.0 \mathrm{~g}$ margarine with $82.82 \mathrm{~g}$ almost consumed twice the rats fed control diet with $42.03 \mathrm{~g}$

\begin{tabular}{|c|c|c|c|c|c|}
\hline Weeks & 5g Margarine & 2.5g Margarine & 5g Canola & 2.5g Canola & Control \\
\hline 1 & 25.02 & 24.71 & 24.77 & 24.63 & 25.08 \\
\hline 2 & 28.28 & 28.23 & 28.23 & 28.86 & 27.34 \\
\hline 3 & 31.74 & 30.54 & 29.33 & 29.48 & 27.4 \\
\hline 4 & 40.41 & 34.19 & 35.94 & 32.96 & 28.36 \\
\hline 5 & 46.65 & 38.43 & 39.3 & 37.5 & 31.65 \\
\hline 6 & 51.33 & 42.21 & 42.69 & 40.86 & 30.33 \\
\hline 7 & 63.95 & 48.97 & 48.58 & 47.54 & 30.19 \\
\hline 8 & 69.62 & 59.46 & 60.23 & 53.46 & 36.2 \\
\hline 9 & 74.12 & 62.75 & 67.22 & 57.03 & 37.48 \\
\hline 10 & 83.82 & 68.91 & 71.75 & 61.17 & 42.03 \\
\hline 11 & 85.2 & 69.63 & 73.77 & 61.8 & 43.92 \\
\hline 12 & 86.4 & 70.8 & 76.05 & 63.3 & 44 \\
\hline
\end{tabular}

Table 6: Weekly food intake of Rattusnorvegicus for twelve weeks.

\begin{tabular}{|c|c|c|c|c|c|}
\hline Variables & Sum of squares & Degree of Freedom & Mean square & F & P-Value \\
\hline Between Groups & 3549.143 & 4 & 887.286 & 3.074 & 0.023 \\
\hline Within Groups & 15877.713 & 55 & 288.686 & & \\
\hline Total & 19426.856 & 59 & & & \\
\hline
\end{tabular}

Table 7: Anova showing the weekly food intake.

\section{Effect of Diet on Weight Gain}

There was significant effect of feeding the animals on different diet on their weight gain. The rat's weight in all the groups showed progressive increase from the fourth week. Rats used were of comparable weight in all the groups initially since they were relatively of the same age. The initial weight of $2.5 \mathrm{~g}$ canola in the diet produced the least mean weight of $71.8 \mathrm{~g}$ rats while the mean weight of the control group had the highest with $73.0 \mathrm{~g}$. The rat with the lowest weight was the first rat in the group fed $2.5 \mathrm{~g}$ canola with $62.0 \mathrm{~g}$ while the rat with the highest weight was the fifth rat in the group fed 


\section{Open Access Journal of Microbiology \& Biotechnology}

$5 \mathrm{~g}$ canola with $85.0 \mathrm{~g}$.

At the end of the $12^{\text {th }}$ week, it was found that the rat fed $5 \mathrm{~g}$ margarine had the highest weight gain compared to other experimental groups which is consistent with the findings of Woods, et al. [11] that compared with low fat-fed controls, Long-Evans rats fed a high fat, lard-based diet exhibited increases of body weight. There was no significant difference observed in the effects of high and low fat diet on the weight gain of albino rats in weeks one to three $(\mathrm{P}>0.05)$, while this was highly significant in the remaining nine weeks, $(\mathrm{P}<0.05)$ at 2-tailed hypothesis testing.

It is observed that the respective $\mathrm{f}$-values for weeks 1,2 and 3 are low. So the $p$-values are not significant. This implies that the mean scores for the weight and body composition of albino rats were nearly the same in each of the three weeks despite the low or high fat diet intake. The relative equal weight in all the experimental groups is due to the fact that the effect of the fat intake has not been felt in their weight. It therefore implies that fat can be accumulated in the body over time without considerable effect on weight gain. Fat can be trapped within the adipose layer and its accumulation over time gives an increase in body weight. Parhofer, et al. [12] carried out similar work and found significant difference between high fat and low fat diet was not detected in the first three weeks but animals on high fat diet showed considerable difference from the fourth week. This ascertains the null hypothesis which states that there is no significant difference in the weight and body composition of albino rats based on low and high fat diet intake. This is true because the effect of the diet intake has not been felt on the weight of the rat.

Meanwhile, the respective f-values $(43.149,110.700$, 96.221, 91.445, 68.525, 45.966, 37.671, 33.835, and 33.082) for week 4,5,6,7,8,9,10,11 and 12 are high and the p-values are also significant. Thus implying the mean scores for the weight and body composition of albino rats was not equal in each of those weeks. The mean score was not just unequal but began to show considerable level of increase. In this respect, the alternative hypothesis is accepted. This also implies that there is significant difference in the weight and body composition of albino rats based on the low and high fat diet intake. It is obvious that the change in weight and body composition of the albino rats started from the fourth week [13].

It could therefore be inferred that it may take some time before the effect of fatty foods can be felt in living organisms. In other words, the effect of fatty foods may not be immediate and therefore it calls for careful attention by human who consume high fatty food diets [14]. Being overweight is not the result of a day's meal, it may take some time but definitely if the fat is not burnt, it may result to being overweight and if the result is not effectively monitored, it will result to obesity and consequently several cardiovascular diseases such as hypertension, diabetics and insulin sensitivity [15].

Apart from the increase noticed in the entire group which became noticeable from the fourth week, the increase in weight observed in rats fed with $5 \mathrm{~g}$ margarine shows a relatively more increase than rats fed with other groups. Rats in this group fell in the group with the highest tertiles of body weight. However, the final weight of the rats obtained in the twelfth week can be used in the classification. The followings are the mean weight of the rats obtained in the twelfth week relative to the diet they were fed with. $5 \mathrm{~g}$ margarine $(240 \mathrm{~g})$, 5 g canola (211.25 g), 2.5 g margarine (196.7 g), 2.5 g canola (175.83 g) and $125 \mathrm{~g}$ for canola.

In models of dietary obesity, animals are classified to prone and resistant based on their body weight, body weight gain, or body fat. Tulipano, et al. [16] categorized SpragueDawley rats fed high-fat diet based on their final body weight, with rats in the highest quartile designated as obesity prone and those in the lowest quartile assigned as obesity resistant. In some studies upper (prone) and lower (resistant) tertiles of body weight gain [17] of the animals fed high-fat diets have been used for this classification. Using the Dourmashkin method of classifying obesity, it can be inferred that rats fed $5 \mathrm{~g}$ margarine and $5 \mathrm{~g}$ canola are obesity prone, those fed 2.5 $\mathrm{g}$ margarine and $2.5 \mathrm{~g}$ canola are intermediate while the rats fed the control are obesity resistant.

According to Aguila and Lacerda, [18] and Woods, et al. [11] fat-enriched diets have been used for decades to model obesity in rodents and it has been observed that the disorders achieved by high-fat feeding resemble the human metabolic syndrome closely and this also may extend to the cardiovascular complications. It can therefore be concluded from the result above that when humans feed continuously on high fat diets such as margarine and canola, they will become prone to obesity.

High fat rats weighed more than low fat controls and defended this weight in the face of changes in energy availability. Comparing these rats with those in the low fat groups, the effects of obesity and dietary composition was observed. This model is therefore well suited for a systematic investigation of the role of dietary fat on body weight regulation and can be applied to many questions that are central to obesity research [19]. Rats consuming high fat diet gained increased body fat relative to rats eating two different low fat diets. The most parsimonious explanation for the ability of the high fat diet to induce obesity is overconsumption of this diet rather than specific metabolic effects of differing proportions of fat and carbohydrate in the 


\section{Open Access Journal of Microbiology \& Biotechnology}

diet. This interpretation is based on the similar body weights and composition of high fat rats compared with rats that were fed with the high fat diet in amounts that were matched the intakes of the low fat group. This is consistent with the findings of James WP [20].

Another possible explanation to why the high fat rats became obese relates to the energy density of the diet. It has been suggested that energy density, rather than simply an increased percentage of dietary fat, is the actual predisposing factor for weight gain in animal. This distinction between energy density and fat percentage is important because in previous studies, when energy density was controlled, it appeared that food intake by animals was regulated primarily by volume [21], a phenomenon that holds for humans as well [22]. The present data are consistent with this interpretation because the increased energy intake by the high fat rats is consistent with the increased energy density of the high diet. The model described by these experiments shares many important features with human obesity. Perhaps most important, the phenomenon is reliable and consistent from one experiment to the next. This validates making comparisons across experiments when the same diets and procedures are used to produce the obese state.

A model of high fat diet-induced obesity having several features that make it useful for investigating the mechanisms by which dietary composition contributes to body weight regulation was developed, of central importance is a comparison of control rats that consume diets differing in percentage of fat and the inclusion of rats with fixed intake of the high fat diet to prevent obesity [23].

\section{Feeding Pattern}

It can be observed from Tables 2 and 3 that the first three weeks of the experimental feeding show no significant difference between the rates of feeding observed in the five experimental groups, their food intake was almost equal despite being fed by different diet. This is consistent with the finding of Olga, et. al. [24] that found out that there is no significant difference between the food intakes of two treatments fed on different diets in their early days of food consumption. This is possibly due to the little or no difference in their individual weight and mean weigh. Starting from the $4^{\text {th }}$ week, appreciable difference was noticed in feed fed high fatty acid based diet compared to those fed low fatty acid based diet as well as the control.

Significant difference was seen between the groups of rats fed low and high saturated fatty diet $(\mathrm{P}<0.05)$. The null hypothesis $\left(\mathrm{H}_{\mathrm{o}}\right)$ that there is no significant difference in the feeding pattern of albino rats fed with low and high saturated fatty diet is thus rejected as the P-value between the groups (0.023) was less than 0.05 (Table 4), hence, the alternative hypothesis $\left(\mathrm{H}_{1}\right)$ that there is significant difference in the feeding habits of the albino rats fed with low and high saturated fatty diet is accepted

\section{Proximate Composition of Rat Carcasses}

From Table 5 the protein and fat accumulation in group three is lowest. Animals in this group are only fed with the basal diet (fibre feed) without adding either margarine or canola. This is responsible for the low level of fat obtained from the proximate composition of the animals and the result of the weight gain taken. The weight gain in this group is the lowest which can be traceable to the low fat taken. Fat intake has an influence on the weight gain of the rats as weight gain is proportionate to fat intake.

It can also be inferred from the Table 5 that the protein and fat accumulation in group 2 which were rats fed $5 \mathrm{~g}$ canola was lesser than those with $5 \mathrm{~g}$ margarine. The value of protein in group two which was the group fed $5 \mathrm{~g}$ canola is15.71 compared to 18.6 in group one which is the group fed $5 \mathrm{~g}$ margarine and the value for fat is 9.97 in group 2 compare to 10.455 in group 1 . This shows a greater percentage of fat and protein in the group fed $5 \mathrm{~g}$ margarine. The effect of this is also revealed in their weight gain as the percentage weight gain in group 2 which is the group fed with $5 \mathrm{~g}$ canola is $191.9 \%$ compare to group 1 (5g margarine) which is $200.8 \%$. This finding reveals that when an organism is fed with a percentage of feed coupled with high percentage of fat intake, there is relative increase in weight.

Slight variation also occurs between the group fed $2.5 \mathrm{~g}$ margarine and $2.5 \mathrm{~g}$ canola. The proximate composition of the group fed $2.5 \mathrm{~g}$ margarine is 15.36 compared to 12.76 of the group fed $2.5 \mathrm{~g}$ canola which also showed in the percentage weight gain of the rats. The group fed 2.5g margarine has a weight gain of $170.9 \%$ compare to the group fed $2.5 \mathrm{~g}$ canola with the weight gain of $144.9 \%$. This also reveals the effect of the diet intake on the weight gain of the rats. The control group had the lowest percent of protein and fat in their diet invariably had the lowest percentage of weight gain with $71.2 \%$.

Both ash and crude fibre in all the groups shows no difference. Crude fibre in all the groups is less than 1 percent, its zero percent in all the groups which ultimately shows that there was no significant difference in the result obtained for crude fibre across the group. The same thing was observed in the percentage of ash. It can be observed that for the entire group, all the rats had approximately two percent which showed that there was no significant difference across the group as it relates to the percentage of ash. The control group had the highest percentage of carbohydrate, followed by $2.5 \mathrm{~g}$ 


\section{Open Access Journal of Microbiology \& Biotechnology}

canola, $2.5 \mathrm{~g}$ margarine, $5 \mathrm{~g}$ canola and $5 \mathrm{~g}$ margarine. Though the difference in the percentage of carbohydrate was not much, yet it exists across the group. It was also clear from the result obtained that the group with the lowest fat had the highest level of carbohydrate which followed the trend across the group. The percentage of moisture is highest in the control group, followed by the group fed with $2.5 \mathrm{~g}$ canola, both the group fed with $5 \mathrm{~g}$ canola and $2.5 \mathrm{~g}$ margarine has the same moisture content and the group with $5 \mathrm{~g}$ margarine had the lowest level of moisture. Since moisture is the water content of the rats, it has no direct effect as to the weight gain of the rats, it only reveals the percentage composition and it is generally believed that water makes up the highest percentage of an organism [10].

Table 6 shows the result of the rat carcasses obtained in the five experimental groups, each group denoting the diet the rats were fed with. The result was presented in duplicate to enhance accuracy and the mean value was taken as presented in Table 7. From the tables 6 and 7, the addition of all the values obtained from the parameters used in finding the proximate composition give an approximate value of hundred percent. The parameters are protein, moisture, fat, ash, crude fibre, carbohydrate, and dry matter. All the values were presented in percentage and the addition of the total value makes hundred percent apart from the dry matter. The dry matter is obtained by subtracting the moisture content from the total values obtained.

The protein and fat level was highest in 5G margarine which revealed why the weight gain in the rat fed $5 \mathrm{~g}$ margarine was visibly higher than the rest dietary treatment. Fats and protein present in the body contribute to the level of weight gained by the living organism. Low and high level of protein contribute to the development of weight gain in the group fed $5 g$ margarine.

\section{Conclusion}

Fat intake determines to a large extent the weight gain by animals as demonstrated by the rat used in the experiment. The content of the food taken by an organism determines to a large extent the weight of such organism, as rats fed with high fat showed a high level of increase compared to those fed with rat low in fat intake. There is strong correlation between the level of fat intake and the weight gain by animals. Being overweight or obese is not just due to genetics, though some are as a result of genetics, lack of physical exercise, reliance on automobiles, the kind of food taken determines to a large extent if an animal will become obese, or overweight. Being obese or overweight is influenced by the volume of food taken as well as the content of the food, i.e., what the food is made up of fat, carbohydrate or protein? Fat can be saturated, monosaturated, poly-saturated fatty acid and all determines the resultant weight of an organism. An animal who consumes high energy dense food, food rich in fat, carbohydrate and protein are known to induce obesity. Fats high in saturated fatty acid based diet readily gain weight compared to those with low saturated fatty acid.

\section{References}

1. Lai M, Chandrasekera PC, Barnard ND (2014) You are what you eat, or are you? The challenges of translating high-fat-fed rodents to human obesity and diabetes. Nutr Diabetes 4(9): e135.

2. Walker KZ, O'Dea K (2001) Is a low fat diet the optimal way to cut energy intake over the long- term in overweight people. Nutr Metab Cardiovasc Dis 11(4): 244-248.

3. Lytle LA (2000) In defense of a low-fat diet for healthy children. J Am Diet Assoc 100(1): 39-41.

4. McManus K, Antinoro L, Sacks F (2001) A Randomized controlled trial of a moderate-fat, low-energy diet compared with a low fat, low-energy diet for weight loss in overweight adults. Int J Obes Relat Metab Disord 25(10): 1503-1511.

5. Corle DK, Sharbaugh C, Mateski DJ, Coyne T, Paskett ED, et al. (2001) Self-rated quality of life measures: effect of change to a low-fat, high-fiber, fruit and vegetable enriched diet. Ann Behav Med 23(3): 198-207.

6. Furnes MW, Zhao CM, Chen D (2009) Development of obesity is associated with increased calories per meal rather than per day. A study of high-fat diet-induced obesity in young rats. Obes Surg 19(10): 1430-1438.

7. Mahan K, Escott-Stump S (2001) Krause's Food, Nutrition, and Diet Therapy. Saunders Company; Philadelphia 82: 666-678.

8. AOAC (1990) Official Methods of Analyst. In: Helrich $\mathrm{K},\left(\right.$ Ed.), $15^{\text {th }}$ (Edn.), Association of Official Analytical Chemist (AOAC), Arlington VA.

9. Labban RSM, Alfawaz H, Almnaizel AT, Hassan WM, Bhat RS, et al. (2020) High-fat diet-induced obesity and impairment of brain neurotransmitter pool. Translational Neuroscience 11(1).

10. Chtourou Y, Kamoun Z, Zarrouk W, Kebieche M, Kallel $C$, et al. (2016) Naringenin ameliorates renal and platelet purinergic signallingalterations in high-cholesterol fed rats through the suppression of ROS and NF- $\kappa$ B signaling pathways. Food Funct 7(1): 183-193.

11. Woods SC, Seeley RJ, Rushing PA, D’Alessio D, Tso P 


\section{Open Access Journal of Microbiology \& Biotechnology}

(2003) Controlled high-fat diet induces obese syndrome in rats. Journal of Nutrition 133(4): 1081-1087.

12. Buettner R, Parhofer K G, Woenckhaus M, Wrede CE, Kunz-Schughart LA, et al. (2006) Defining high-fat-diet rat models: metabolic and molecular effects of different fat types. J Mol Endocrinol 36(3): 485-501.

13. Enos RT, Velazquez KT, Murphy EA (2014) Insight into the impact of dietary saturated fat on tissue-specific cellular processes underlying obesity-related diseases. J Nutr Biochem 25(6): 600-612.

14. Kahle M, Schafer A, Seelig A, Schultheiss], WuM, et al. (2015) High fat diet-induced modifications in membrane lipid and mitochondrial-membrane protein signatures precede the development of hepatic insulin resistance in mice. Mol Metab 4(1): 39-50.

15. Enos RT, Davis JM, Velazquez KT, McClellan JL, Day SD, et al. (2013) Influence of dietary saturated fat content on adiposity, macrophage behavior, inflammation, and metabolism: composition matters. J Lipid Res 54(1): 152-163.

16. Tulipano G, Vergoni AV, Soldi D, Muller EE, Cocchi D (2004) Characterization of the resistance to the anorectic and endocrine effects of leptin in obesity prone and obesity-resistant rats fed a high-fat diet. J Endocrinol 183(2): 289-298.

17. Dourmashkin JT, Chang GQ, Hill JO, Gayles EC, Fried SK, et al. (2006) Model for predicting and phenotyping at nonnal weight the long term propensity for obesity in sprague-dawley rats. Physiol Behav 87(4): 666-678.

18. Aguila MB, Lacerda CA (2003) Heart and blood pressure adaptations in Wistar rats fed with different high-fat diets for 18 months. Nutrition 19(4): 347-352.

19. Franko A, von Kleist-Retzow JC, Neschen S, Wu M, Schommers P, et al. (2014) Liver adapts mitochondrial function to insulin resistant and diabetic states in mice. J Hepatol 60(4): 816-823.

20. James WPT (2008) The fundamental drivers of the obesity epidemic. Obes Rev 9(S1): 6-13.

21. Poppitt SD (1995) Energy density of diets and obesity. Int J Obes Relat Metab Disord 19(S5): S20-S26.

22. Rolls BJ, Shide D, Boros J (1999) Dietary fat and control of food intake in appetite and body Weight Regulation: Sugar, Fat and Macronutrient Substitutes. European Journal of Clinical Nutrition 53(S1): S176-S181.

23. Ho JH, Lee OK, Fu YJ, Shih HT, Tseng CY, et al. (2013) An iTRAQ proteomic study reveals an association between diet-induced enhanced fatty acid metabolism and the development of glucose intolerance in prediabetic mice. J Proteome Res 12(3): 1120-1133.

24. Olga D, Isabelle M, Stanley DG (2010) Resistance of male Sprague-Dawley rats to sucrose induced obesity: Effects of 18-methoxycoronaridine. Physiol Behav 102(2): 126131. 